\author{
Jurnal Mekanova \\ Vol 5. No. 1, April 2019
}

ISSN : 2502-0498

\title{
Penentuan Sudut Kemiringan Optimal Panel Surya Untuk Wilayah Meulaboh
}

\author{
Syurkarni Ali ${ }^{1}$, T.M. Azis Pandria ${ }^{2}$ \\ ${ }^{1}$ Dosen Teknik Mesin - Universitas Teuku Umar - Meulaboh \\ Jurusan Mesin, FTEKNIK UTU, Meulaboh \\ e-mail: charnie_ali@yahoo.com ${ }^{1}$, azispdr@gmail.com²
}

\begin{abstract}
Development of energy especially alternative energy and renewables continue to be encouraged, one of which is becoming the trend of the world today is focused towards the development of solar energy. The optimum angle of tilt of the photovoltaic panel is one of the deciding factor against the acceptance of the amount of solar radiation in the amount of the maximum, so that will affect the power output of a photovoltaic panel. Method of calculation of the Altitude angle is a way to find out the optimum height of the positions of the Sun, and these factors influence the position of the slope of the surface of the panel sector in the region, so by knowing the position of the right angle of the Sun will be able to obtain the maximum amount of radiation against photovoltaic panels. Adjustment of the angle of the slope against the monthly solar panels in the region of Meulaboh is affected by the angle of altitude. January and March, the optimum angle value starts from 35,54 to $12,39^{\circ}$. April does not occur, because of the angle position of the panel surface horizontal is same. May to December, the orientation of the panel turned south-facing surface of the panel with face down which is characterized by a negative notation.
\end{abstract}

Keywords - the photovoltaic panels, the altitude angles, optimal angle, orientation

\section{PENDAHULUAN}

Dewasa ini energi sangat berperan penting terhadap peningkatan sosial, ekonomi dan lingkungan dalam keberlanjutan pembangunan. Secara umum konsumsi energi di indonesia terus meningkat, sejalan dengan laju pertubuhan ekonomi dan pertambahan jumlah penduduk. Diperlukan akses terhadap energi yang handal sebagai syarat peningkatan standar hidup masyarakat. Pengembangan terhadap energi terutama energi alternatif dan terbarukan terus digalakkan, seperti halnya panas bumi, angin, air dan surya. Salah satu yang sedang menjadi trend dunia saat ini adalah fokus terhadap pengembangan energi surya, yang dipercaya sebagai energi abadi yang tersedia dalam waktu tak terbatas. Penggunaan energi surya menjadi energi listrik dilakukan melalui perangkat konversi yang disebut sel surya [1].

Sudut kemiringan optimal panel surya merupakan salah satu faktor penentu terhadap penerimaan jumlah radiasi surya dalam jumlah maksimal, sehingga akan berdampak terhadap daya keluaran panel surya. Oleh karena itu diperlukan suatu studi untuk dapat mengetahui posisi sudut kemiringan optimal panel surya terhadap posisi sinar surya yang datang terhadap permukaan panel surya. Posisi surya yang tidak konstan sangat berpengaruh terhadap bumi, sehingga dibutuhkan analisa aktual sudut matahari terhadap panel surya sepanjang tahun yang disesuaikan dengan latitude lokasi. Analisa yang dihasilkan sangat diperlukan pada perencanaan sebuah sistem instalasi panel surya [2]. Energi radiasi surya terhadap bumi cenderung konstan saat cuaca cerah, dan energi yang diterima pada suatu wilayah sangat dipengaruhi oleh kondisi klimatologi seperti kepadatan awan dan curah hujan dan temparatur lingkungan sekitar. Altitude angle merupakan faktor yang mempengaruhi posisi matahari terhadap permukaan panel disuatu wilayah, sehingga 


\section{Jurnal Mekanova \\ Vol 5. No. 1, April 2019 \\ ISSN : 2502-0498}

dengan mengetahui posisi ketinggian matahari yang tepat akan dapat memperoleh jumlah radiasi maksimal terhadap panel surya [3]. Pengumpulan jumlah radiasi dalam jumlah maksimal akan berpengaruh terhadap daya keluaran panel surya, sehingga efesiensi panel surya menjadi meningkat [1].

Telah banyak penelitian yang dilakukan untuk mengetahui sudut optimal panel surya agar mendapatkan jumlah keluaran daya maksimal yang disesuiakan berdasarkan lokasi, diantaranya panelitian yang dilakukan Tamer Khatib, et al. [4] melakukan perhitungan terhadap sudut optimal panel surya setiap bulan terhadap lima tempat berbeda di Malaysia menggunakan pemodelan terhadap radiasi surya dengan memperhitungkan radiasi global, radiasi tersebar dan radiasi pantulan pada bidang miring. Qian Zhao et. Al [2] melakukan perhitungan sudut kemiringan optimal panel surya berdasarkan prediksi radiasi matahari. Penelitian ini dilakukan di Singapura, dengan memperhitungkan pengaruh cuaca terhadap penyimpangan hasil radiasi surya dari kondisi ideal saat cuaca cerah dan dilakukan analisa pada periode bulanan, menggunakan metode autoregressive dan moving average (ARMA) untuk pemodelan indeks menggunakan prediksi radiasi. Aditya Rachman [5] melakukan optimalisasi energi surya berdasarkan penyesuaian posisi bulanan. Penelitian ini dilakukan di Sulawesi Tenggara dengan menggunakan pemodelan matematis terhadap radiasi matahari pada bidang miring yang dihitung secara terpisah diantaranya perhitungan terhadap radiasi langsung, tersebar dan terpisah untuk mengetahui jumlah total radiasi datang dengan mempertimbangkan posisi sudut deklinasi surya. Belkacem Ihya et al. [6] melakukan perhitungan terhadap sudut kemiringan optimal kolektor surya yang dihadapkan ke utara. Penelitian ini dilakukan di kota Fez Maroko, dimana radiasi tersebar dan radiasi global harian pada kolektor selama 12 bulan di tahun 2012. Menggunakan perkiraan total radiasi surya hanya pada satu orientasi yang menghadap ke utara dengan berbagai sudut kemiringan permukaan kolektor yang dimulai dari $20^{\circ}$ sampai $90^{\circ}$. Menggunakan data pengukuran yang telah dikumpulkan sesuai posisi kota Fez Maroko (latitude $33^{\circ} 56^{\prime} \mathrm{N}$, longitude $4^{\circ} 99^{\prime} \mathrm{W}$, altitude: $579 \mathrm{~m}$ ) sepanjang periode 1 Januari sampai Desember 2012. Pengumpulan data menggunakan perangkat Pyranometer untuk menghitung iradiasi global pada permukaan horizontal dan bidang miring pada posisi $34^{\circ}$ menghadap utara. Pembangkit listrik tenaga surya merupakan suatu potensi strategis untuk dikembangkan, terutama bagi wilayah Meulaboh $\left(4.1437^{\circ} \mathrm{N}, 96.1281^{\circ} \mathrm{E}\right)$ yang berada dekat dengan equator sehingga memiliki potensi penyinaran maksimal sepanjang tahun. Agar mendapatkan radiasi maksimal sepanjang tahun, maka diperlukan penelitian posisi altitude angle saat siang tengah hari untuk wilayah Meulaboh untuk dapat menentukan sudut optimal kemiringan panel surya.

\section{METODE PENELITIAN}

Metode yang digunakan pada penelitian ini menggunakan metode matematis untuk menentukan sudut altitude matahari di wilayah Meulaboh. Selain sudut deklinasi, sudut lain yang turut diperhitungkan adalah deklinasi, dimana sudut ini saling berhubungan dengan sudut altitude matahari.

\section{A. Orbit bumi}

Orbit bumi terhadap matahari membentuk bidang elips dalam sekali revolusi bernilai 365,25 hari. Sebenarnya tingkat elips orbit bumi kecil dan bisa dikatakan hampir mendekati bentuk bulat melingkar. Titik terdekat yang antara bumi dan matahari terjadi pada tanggal 2 Januari dengan nilai terdekat 147 juta kilometer. Disisi lainnya titik terjauh terjadi pada tanggal 3 juli dimana jarak saat itu sekitar 152 juta kilomter terhadap matahari. Variasi nilai ini sebagimana dijelaskan oleh persamaan 3 [3].

$$
=1,5 \times 10^{8}\{1+0,017 \sin [360(-93)]\}
$$


Jurnal Mekanova

Vol 5. No. 1, April 2019

ISSN : 2502-0498 


\section{Jurnal Mekanova \\ Vol 5. No. 1, April 2019 \\ ISSN : 2502-0498}

Dimana $n$ merupakan jumlah hari yang dimulai tanggal 1 Januari dan tanggal 31 Desember menjadi hari yang ke 365, seperti tampak pada tabel 1.

Tabel 1. Urutan hari untuk setiap bulan [3]

\begin{tabular}{llll}
\hline January & $n=1$ & July & $n=182$ \\
February & $n=32$ & August & $n=213$ \\
March & $n=60$ & September & $n=244$ \\
April & $n=91$ & October & $n=274$ \\
May & $n=121$ & November & $n=305$ \\
June & $n=152$ & December & $n=335$
\end{tabular}

Setiap hari bumi berputar pada sumbunya sambil melakukan orbit sepanjang elips. seperti yang ditunjukkan gambar 1 dimana sepanjang bidang orbit bumi disebut bidang ekliptik. bumi berputar dengan kemiringan 23.45 terhadap bidang edar dengan sudut kemiringan tersebut. hal ini yang menyebabkan pergantian musim dimana saat 21 maret dan 21 september garis dari pusat matahari ke bumi melewati equator diseluruh bagian bumi sehingga terjadi pola ekuinok, dimana terjadi kesetaraan waktu antara siang dan malam yaitu sama - sama 12 jam. Pada tangggal 21 Desember musim dingin terjadi di utara bumi, dimana kemiringan kutub utara mencapai sudut tertinggi terhadap matahari (23.45) sementara pad 21 juni terjadi proses sebaliknya [3].

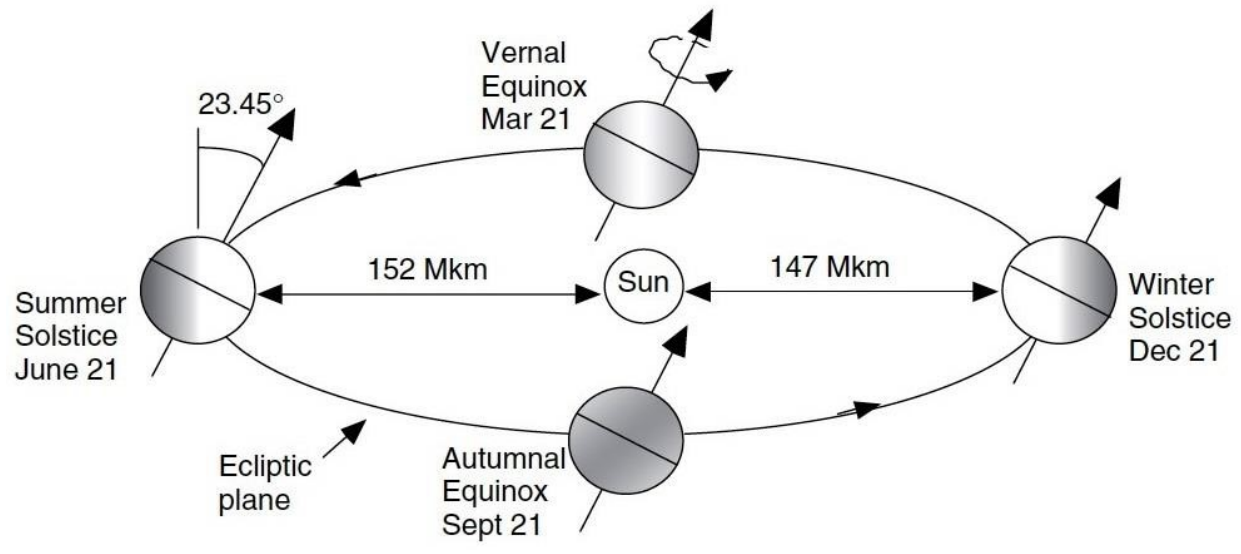

Gambar 1. Sudut Putar Bumi Terhadap Bidang Orbit [3]

B. Perhitungan Sudut Deklinasi $(\delta)$

Seperti diketahui bahwa matahari terbit di timur dan terbenam dibarat, mencapai titik tertinggi tepat saat siang hari. Hal ini sangat berguna untuk memprediksi secara tepat posisi matahari dilangit disetiap lokasi setiap hari dalam setahun. Sebagai contoh penggunaan informasi sudut matahari untuk membantu menentukan kemiringan panel surya guna mendapatkan paparan radiasi maksimal. Pengaruh dari orbit tadi membentuk sudut antara bidang equator dengan garis yang ditarik dari pusat matahari ke bumi yang disebut deklinasi matahari $(\delta)$ yang nilainya bervariasi ekstrim $\pm 23,45^{\circ}$ dan dapat ditentukan dengan persamaan berikut 1 dimana $n$ merupakan jumlah hari dalam setahun $(n=1$ pada 1 Januari) [3].

$$
=23.45^{\circ} \sin \left[\frac{360}{365}(-81)\right]
$$




\section{Jurnal Mekanova \\ Vol 5. No. 1, April 2019 \\ ISSN : 2502-0498}

Gambar 2. Menunjukkan sudut yang terbentuk antara bidang orbit equator dan garis yang ditarik dari pusat bumi ke pusat matahari. Nilai tepat dari deklinasi sedikit bervariasi dari tahun ke tahun, secara detil dapat ditemui pada The American Ephemeris and Nautical Almanac [3].

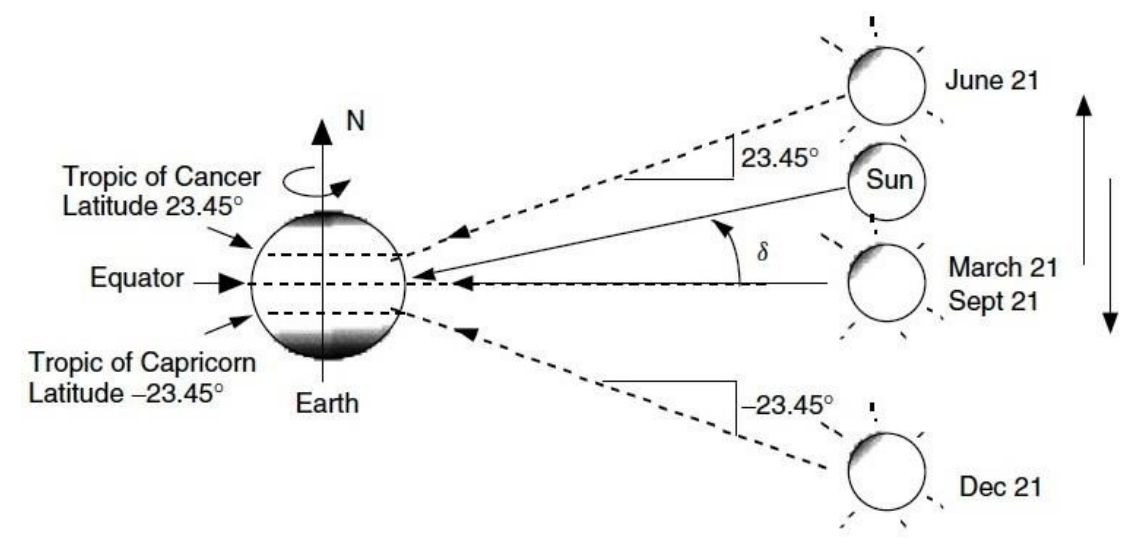

Gambar 2. Pandangan alternatif terhadap hubungan bumi - matahari [3].

C. Perhitungan Sudut Altitude $\left(\beta_{N}\right)$

Saat siang hari matahari mencapai titik tertinggi dan merupakan titik referensi penting untuk hampir semua perhitungan matahari. Rata -rata panel surya di posisikan menghadap equator, bagi belahan utara bumi menghadap ke selatan, sedangkan bagi belahan selatan bumi menghadap ke utara. Konfirugasi lainnya adalah memiringkan panel surya pada sudut kemiringan tertentu yang sama dengan latitude lokasi, merupakan cara terbaik untuk mendapatkan jumlah radiasi maksimal yang terpapar ke permukaan panel surya. Garis yang ditarik dari sistem bumi - matahari seperti pada gambar 1 bisa mempermudah pemetaan sudut matahari, yang disebut altitude angle $\left(\beta_{N}\right)$. Ketinggian sudut antara matahari dan equator lokal berada langsung dibawah matahari, berdasarkan gambar 3 dapat ditulis hubungan altitude angle dengan lokasi sudut deklinasi dimana $L$ merupakan latitude lokasi [3].

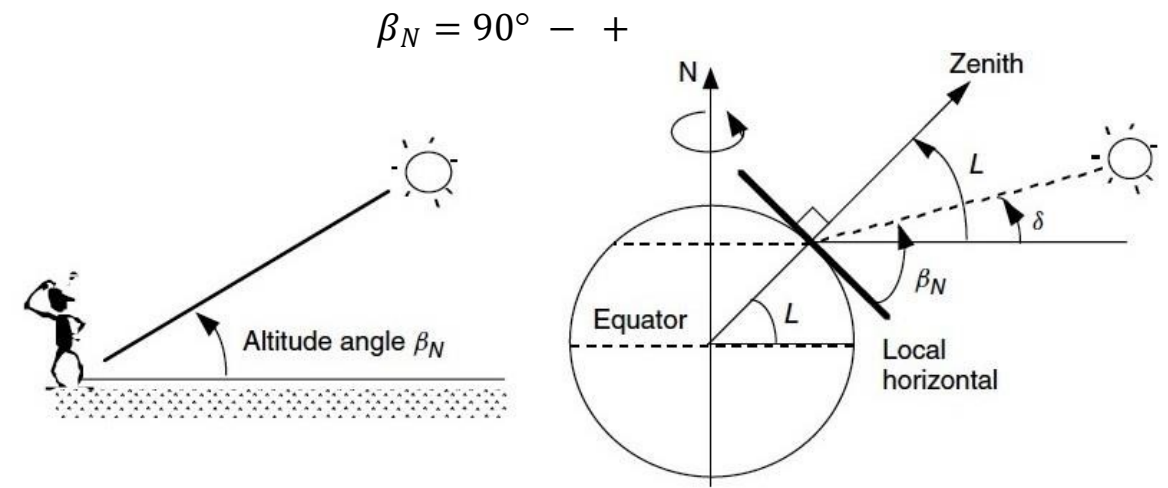

Gambar 3. Altitude angle saat matahari siang hari [3].

D. Jalur Matahari (sun path)

Pergeseran sudut optimum panel surya dipengaruhi oleh pergerakan matahari dilangit, yang ikut mempengaruhi sudut kemiringan panel surya sehingga perubahan tersebut ikut mempengaruhi terhadap penerimaan jumlah radiasi matahari pada panel surya. Jumlah radiasi langsung dengan posisi datang tegak lurus terhadap panel atau membentuk sudut $90^{\circ}$. Saat jalur pergerakan matahari berada disebelah utara bumi, maka panel harus 


\section{Jurnal Mekanova \\ Vol 5. No. 1, April 2019 \\ ISSN : 2502-0498}

diarahkan ke utara, dan saat itu bernilai positif. Saat jalur pergerakan matahari berada dibelahan selatan bumi, maka panel harus diarahkan ke selatan, saat itu bernilai negatif seperti tampak pada gambar 4 [5]. Dengan memahami jalur pergerakan matahari kita juga dapat menentukan pola bayangan yang akan terjadi pada benda, sehingga dalam perencanaan intalasi panel surya, hal ini juga harus diperhatikan. Bila bayangan yang akan terjadi menghalangi permukaan panel, maka posisi permukaan panel dapat dipindahkan dari sumber bayangan didepannya. Analisa banyangan perlu dilakukan dengan rentang waktu selama 12 bulan, atau masa satu tahun [3].

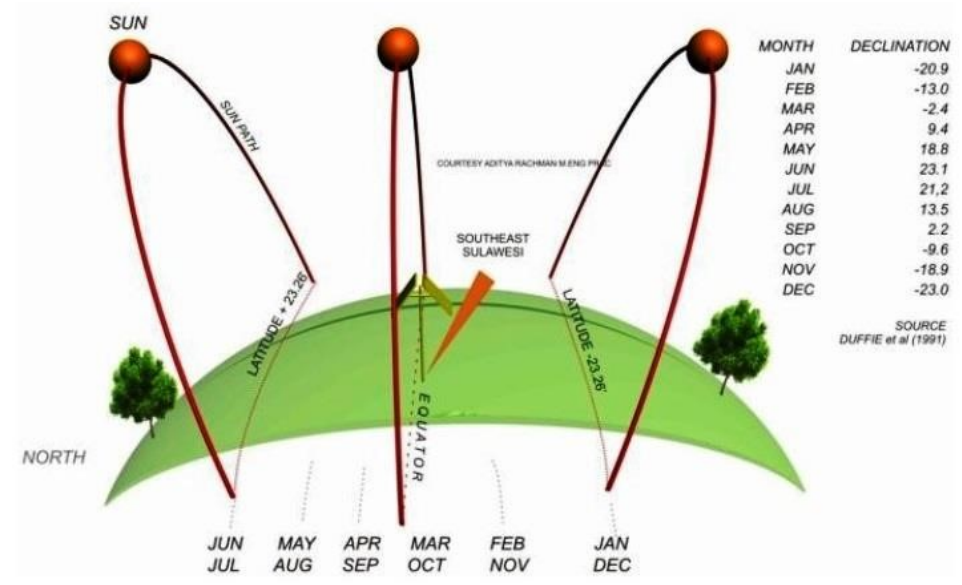

Gambar 4. Jalur Pergerakan Matahari dalam Setahun [5].

\section{HASIL DAN PEMBAHASAN}

A. Perhitungan Sudut Deklinasi

Berdasarkan tinjauan teoritis yang telah dipaparkan diatas, dapat ditentukan nilai sudut deklinasi untuk 12 bulan, seperti tampak pada tabel 2 .

Tabel 2. Nilai sudut deklinasi bulanan

\begin{tabular}{|l|l|l|c|}
\hline No. & \multicolumn{1}{|c|}{ Bulan } & \multicolumn{1}{c|}{$n$} & Nilai $\delta$ (derajat) \\
\hline 1 & Januari & 1 & $-31,39$ \\
\hline 2 & Februari & 32 & $-19,24$ \\
\hline 3 & Maret & 60 & $-8,25$ \\
\hline 4 & April & 91 & 3,93 \\
\hline 5 & Mei & 121 & 15,69 \\
\hline 6 & Juni & 152 & 27,87 \\
\hline 7 & Juli & 182 & 39,65 \\
\hline 8 & Agustus & 213 & 51,80 \\
\hline 9 & September & 244 & 63,97 \\
\hline 10 & Oktober & 274 & 75,76 \\
\hline 11 & November & 305 & 87,92 \\
\hline 12 & Desember & 335 & 99,69 \\
\hline
\end{tabular}

Dari tabel 2 dapat dilihat hasil perhitungan sudut deklinasi setiap bulan dari Januari hingga Desember. Januari hingga Maret kemiringan matahari berada disisi selatan bumi sehingga bernilai 'min'. Bulan April hingga Desember matahari telah berada disisi utara bumi sehingga nilai sudut deklinasi menjadi 'plus'.

B. Perhitungan sudut altitude

Berdasarkan tinjauan teoritis yang telah dipaparkan diatas, dapat ditentukan nilai altitude matahari selama 12 bulan, berlaku di wilayah Meulaboh seperti tampak pada tabel 3. 


\section{Jurnal Mekanova \\ Vol 5. No. 1, April 2019 \\ ISSN : 2502-0498}

Tabel 3. Nilai altitude angle saat tengah hari

\begin{tabular}{|l|c|c|}
\hline No & $\begin{array}{l}\text { Altitude angle matahari }\left(\beta_{N}\right) \\
\text { tengah hari }\end{array}$ & Bulan \\
\hline 1 & 54,45 & Januari \\
\hline 2 & 66,63 & Februari \\
\hline 3 & 77,62 & Maret \\
\hline 4 & 89,79 & April \\
\hline 5 & 101,65 & Mei \\
\hline 6 & 113,73 & Juni \\
\hline 7 & 125,49 & Juli \\
\hline 8 & 135,67 & Agustus \\
\hline 9 & 149,84 & September \\
\hline 10 & 161,60 & Oktober \\
\hline 11 & 173,78 & November \\
\hline 12 & 185,56 & Desember \\
\hline
\end{tabular}

Dari tabel 3 dapat dilihat hasil perhitungan sudut altitude matahari setiap bulan dari Januari hingga Desember. Nilai ini hanya berlaku unutk wilayah Meulaboh. Nilai terendah terjadi pada bulan Januari dan tertinggi terjadi pada bulan Desember. Perhitungan sudut ini berhubungan dengan sudut deklinasi dan latitude wilayah Meulaboh.

C. Nilai sudut optimal panel surya

Berdasarkan tinjauan teoritis yang telah dipaparkan diatas, dapat ditentukan nilai kemiringan optimal panel saat siang hari selama 12 bulan, untuk wilayah Meulaboh seperti tampak pada tabel 4 .

Tabel 4. Sudut optimal panel saat tengah hari

\begin{tabular}{|c|c|}
\hline $\begin{array}{c}\text { Sudut kemiringan panel } \\
\text { surya }\left(\beta_{\text {opt }}\right) \text { tengah hari }\end{array}$ & Bulan \\
\hline 35,54 & Januari \\
\hline 23,38 & Februari \\
\hline 12,39 & Maret \\
\hline 0,22 & April \\
\hline$-11,56$ & Mei \\
\hline$-23,73$ & Juni \\
\hline$-35,49$ & Juli \\
\hline$-47,67$ & Agustus \\
\hline$-59,84$ & September \\
\hline$-71,60$ & Oktober \\
\hline$-83,77$ & November \\
\hline$-95,56$ & Desember \\
\hline
\end{tabular}

Dari tabel 4 dapat dilihat hasil perhitungan sudut optimal panel surya saat tengah hari di wilayah Meulaboh. Nilai ini hanya berlaku untuk wilayah Meulaboh. Nilai terendah terjadi pada bulan Januari dan tertinggi terjadi pada bulan Desember. Perhitungan sudut ini berhubungan dengan sudut deklinasi dan latitude wilayah Meulaboh.

Berdasarkan tinjauan teoritis yang telah dipaparkan diatas, dapat ditentukan sudut kemiringan optimal untuk permukaan panel surya di wilayah Meulaboh (latitude $4.1437^{\circ}$ ). Perubahan sudut kemiringan panel surya berdasarkan penyesuaian bulanan, seperti tampak pada gambar 4, bervariasi nilainya. Hal ini dipengaruhi oleh sudut altitude matahari, yang terjadi pada bulan Januari hingga Maret, orientasi panel menghadap utara dengan nilai 


\section{Jurnal Mekanova \\ Vol 5. No. 1, April 2019 \\ ISSN : 2502-0498}

sudut optimal $35,54^{\circ}, 23,38^{\circ} 12,39^{\circ}$. Khusus pada bulan April, posisi kemiringan panel tidak terjadi, atau sudut panel surya berhimpit dengan permukaan horizontal, atau $\beta_{\text {opt }}=0^{\circ}$. Dimulai dari bulan Mei hingga Desember orientasi panel berubah ke selatan bumi, dengan posisi sudut sudah bernilai negatif sehingga permukaan panel mulai membentuk sudut 11,56 dibulan Mei - 23, 73 untuk bulan Juni, - 35, 49 untuk bulan Juli, - 47, 67 untuk bulan Agustus, - 59,84 untuk bulan September, - 71, 60 untuk bulan Oktober, - 83,77 untuk bulan November dan -95, 56 untuk bulan Desember. Pada posisi ini kondisi panel menghadap kebawah.

Penyesuaian posisi panel dilakukan agar permukaan panel tepat menghadap matahari saat siang hari, sehingga panel mendapatkan sudut optimal. Nilai sudut kemiringan optimal dan nilai altitude matahari saat siang hari sebagaimana tampak pada tabel 1.

Gambar 5 menampilkan perbedaan sudut yang terjadi pada permukaan horizontal berbeda terhadap matahari, dimana bila dilihat dari sudut altitude $\left(\beta_{N}\right)$ saat siang hari sudut yang terbentuk lebih besar bila dibandingkan dengan sudut kemiringan panel terhadap permukaan horizontal. Namun demikian kedua sudut tersebut saling berhubungan dalam perhitungan penentuan sudut kemiringan panel surya pada posisi optimal saat siang hari.

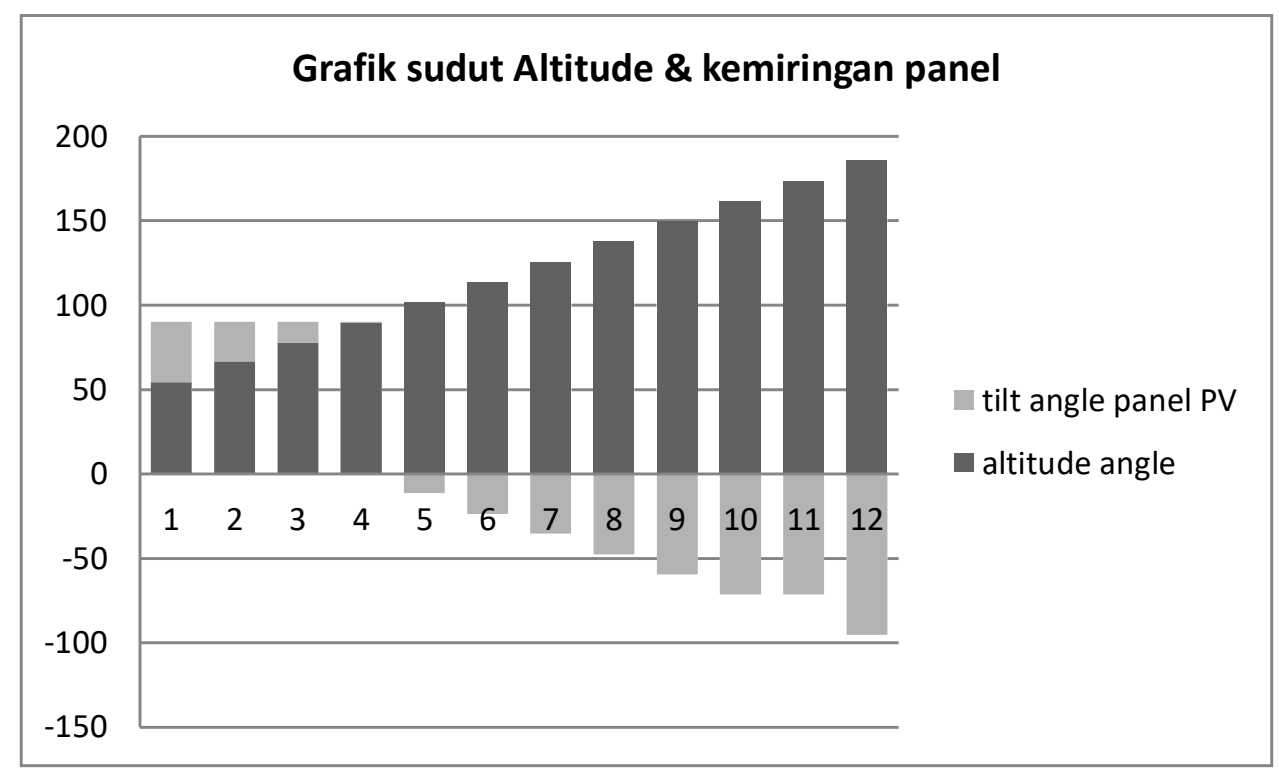

Gambar 5. Grafik perbanding sudut altitude dengan sudut kemiringan panel

\section{KESIMPULAN}

Perhitungan sudut kemiringan optimal panel surya di wilayah Meulaboh telah dilakukan pada penelitian ini. Berikut beberapa simpulan yang dapat ditarik dari panelitina ini :

- Pada bulan Januari hingga Maret posisi panel surya menghadap tepat ke utara dengan sudut kemiringan $35,54^{\circ}, 23,38^{\circ}$ dan $12,34^{\circ}$.

- Khusus pada bulan April sudut kemiringan bernilai $0,22^{\circ}$ yang berarti posisi panel surya berhimpit dengan bidang horizontal.

- Pada bulan Mei hingga Desember posisi panel mulai menghadap ke bawah, atau permukaan panel mulai menghadap ke arah selatan dari latitude Meulaboh, hal ini ditandai dengan notasi 'min' pada awalan nilai sudut.

- Sudut optimal yang diperoleh merupakan nilai optimal saat siang hari, yang berarti posisi matahari tegak lurus terhadap panel. 


\section{Jurnal Mekanova \\ Vol 5. No. 1, April 2019 \\ ISSN : 2502-0498}

- Penerapan nilai sudut optimal terhadap instalasi panel surya dapat meningkatkan penerimaan radiasi langsung dari matahari.

- Antara sudut altitude matahari dengan sudut deklinasi saling berhubungan dalam metode perhitungan, untuk mendapatkan nilai sudut kemiringan panel surya.

- Metode ini merupakan perhitungan matematis dengan keluaran berupa nilai tertentu tanpa melihat faktor lain yang mempengaruhi sudut kemiringan optimal, seperti faktor cuaca, jumlah radiasi dan lainnya.

\section{SARAN}

Disarankan bagi peneliti yang melanjutkan penelitian ini untuk mempertimbangkan faktor sudut jam matahari $(\omega)$ pada latitude lokasi yang diteliti. Penelitian ini hanya menggunakan metode perhitungan terhadap altitude angle matahari saat siang hari, artinya nilai sudut yang dihasilkan mengesampingkan faktor lain yang mempengaruhi jumlah radiasi pada bidang miring. Faktor penting lainnya yang harus mempertimbangkan adalah pengaruh dari iklim setempat. Faktor tersebut dapat ditentukan menggunakan metode perhitungan faktor geografis $\left(R_{b}\right)$ atau penentuan sudut deklinasi sebagai pembanding nilai sudut optimal. Penggunaan software untuk mendapatkan nilai maksimal pada bidang miring dimungkinkan penggunaannya seperti Matlab. Metode yang digunakan pada penelitian ini juga dapat dibandingkan dengan metode pengukuran langsung dilapangan.

\section{DAFTAR PUSTAKA}

[1] Akbar Naro .P. dan Syukri. H., "Analisis Efisiensi Terbaik Pada Instalasi Panel Surya dengan Unit Motor-Pompa DC," Energi, Universitas Hasanuddin, 2010.

[2] Qian Zhao, Peng Wang and Lalit Goel, "Optimal PV panel tilt angle based on solar radiation prediction," 2010 IEEE 11th International Conference on Probabilistic Methods Applied to Power Systems, pp. 425-430 Singapore, 2010.

[3] Gilbert M. Masters, Renewable and Efficient Electric Power Systems, John Wiley \& Sons, Inc., 2004.

[4] T. Khatib, A. Mohamed and K. Sopian, "On the monthly optimum tilt angle of solar panel for five sites in Malaysia," 2012 IEEE International Power Engineering and Optimization Conference Melaka, Malaysia, Melaka, 2012, pp. 7-10.

[5] A. Rachman, "Optimalisasi Teknologi Energi Surya Berbasis Penyesuaian Posisi Panel Bulanan di Sulawesi Tenggara," J. Teknol. Univ. Muhammadiyah Jakarta, vol. 8, no. 1, pp. 1-8, 2016.

[6] A. Mechaqrane, R. Tadili, and M. N. Bargach, "Optimal tilt angles for solar collectors facing south at Fez city ( Morocco )," Journal of Natural Sciences Research, vol. 4, no. 10, pp. 120-128, 2014. 